\title{
I'm not Alone: A Phenomenological Study of Psychological Help Sources in Suicide Crisis
}

\author{
F. A. Nurdiyanto ${ }^{1}$, Subandi ${ }^{2}$ \\ 1,2Faculty of Psychology, Universitas Gadjah Mada \\ ${ }^{1}$ Faculty of Psychology, Universitas Kristen Satya Wacana
}

Submitted 15 July 2021 Accepted 21 September 2021 Published 30 October 2021

\begin{abstract}
This research was conducted to explore the experiences of suicide survivors in seeking psychological help for their crisis. A descriptive phenomenological study was chosen to get the dynamics of mental health help-seeking. Semi-structured interviews were conducted with youth participants who had previously experienced a suicide crisis. Seven participants ( 5 women; $\bar{x} 26$ years) were involved voluntarily through the snowball technique recruitment. Descriptive phenomenological analysis was applied to get the synthesis and meaning of experiences in psychological help-seeking. This study found psychological help sources: self-help, close relationships, socio-cultural, and institutional. This article highlighted that social relations played a crucial role in the success of seeking help. Suicide prevention should be carried out by campaigning for self-disclosure to seeking help by utilizing various available psychological help sources.
\end{abstract}

Keywords: descriptive phenomenological method; mental health help-seeking; suicide

The global death prevalence caused by suicide shows a devastating state. Suicide has been placed in the 20th spot for the cause of deaths globally, exceeding deaths caused by malaria, breast cancer, war, and terrorism act (World Health Organization [WHO], 2021). Although women are known to have a higher prevalence of suicide (Freeman et al. 2017), deaths and fatalities of suicide are dominated by men (12.6) compared to women (5.4; WHO, 2021). The rate of suicide in Indonesia was also reported to reach $2.6 \%$ with an average of more than 6,500 incidents per year, which contributed to $0.58 \%$ of the cause of deaths in Indonesia (WHO, 2021).

Suicide is a silent killer and becomes the second common cause of death in young people (15 to 29 years old) after traffic accidents (WHO, 2021). Additionally, in the Global School-based Student Health Survey (GSHS), 5.14\% of high school students were estimated to have serious suicide ideation and drive in the past year (Ministry of Health Republic of Indonesia, 2016). This condition further shows the bleakness of mental health problems among youths.

An individual who experiences a suicide crisis is more prone to encounter failure in accessing psychological help. Systematic reviews disclosed that three out of four people who commit suicide have never accessed the help of mental health professionals before ending their lives (Luoma et al., 2002) and more than 50\% of them did not discuss their issue with other medical personnel (Owens et al., 2005). Cornally and McCarthy (2011) 
concluded that young people are less likely to seek help, instead of hiding or neglecting their problems. Most people who commit suicide do not seek help from a mental health professional at all, especially when they make a decision and plan on how to end their lives (Pitman \& Osborn, 2011).

The help seeker faces complicated issues, internally and in the system structure. Czyz et al. (2013) reported that independent problem management is the main option, considering that the issues being faced are perceived to be too trivial to involve other people and professionals. The involvement of external parties is considered to have a consequence in the loss of money and time. Additionally, a low likelihood to seek professional psychological help seems to be caused by negative attitudes and doubt towards mental health institutions and the efficacy of interventions (David, 2010).

Help-seeking is an active effort in finding various resources that can act as the resolution for various problems being faced. Barker (2007) considered that help-seeking is an adaptive coping strategy to reduce distress and increase psychological welfare. This action is done to obtain advice, suggestions, information, intervention, to professional references. Help from a suitable source can prevent the onset of more complex distress, encourage adjustment, and reduce emotional and behavioral problems (Rickwood \& Thomas, 2012). Help-seeking is a transaction between personal domain and social interaction that can facilitate or inhibit treatment-seeking (Seamark \& Gabriel, 2018). By communicating problems and distressing experiences to others, an individual with a suicide crisis can obtain help or support in form of emphatic understanding and even therapeutic intervention.

The sources of psychological help-seeking are varied. Help-seeking generally refers to the utilization of support and aid from: 1) formal sector, which by Barker et al. (2005) is classified into various forms of health services or social institutions conducted professionally (psychiatrist, psychologist, counsellor, doctor, social worker); 2) source of informal help (family, friends, parents); and semi-formal (school, workplace). On the other hand, Barker (2007) categorized the source of help according to: 1) specific health needs (e.g., visiting doctor, psychologist, psychiatrist, and midwife); 2) help-seeking for general needs (e.g., asking help to finish tasks); and 3) help-seeking to deal with familial and relational problems).

Cultural difference influences the variations of help-seeking behavior concerning mental health issues. The differences in health beliefs also construct help-seeking behavior in solving psychological problems (Gilchrist \& Sullivan, 2006). Javanese people, for example, use traditional, religious, or alternative treatments and therapies to solve various psychological crises (Subandi et al., 2020). The users of non-professional help also spread across varied backgrounds, not only from the illiterate or low socioeconomic circle (Nurhayati \& Widowati, 2017). The help-seeking behavior also remains to have formidable issues, considering that the availability and ease of access to mental health services are very limited, and the distribution is unequal (Human Rights Watch, 2016). 
Suicide possesses several characteristics that have been occurring since the fatal wish and ideas arise, so the involvement of mental health personnel becomes really crucial in its treatment (Giner et al., 2016). However, the study of psychological help-seeking, particularly within the context of suicide has not been thoroughly explored yet. Studies about help-seeking in mental health need to be done to identify various potentials and the source of success in psychological help-seeking for people who experience suicide crises and other mental health problems. It is necessary to conduct studies to understand the process of psychological help-seeking and factors that support or inhibit that action.

The study was done to explore the dynamic of seeking professional help done by suicide survivors with a phenomenological perspective. It focused on the survivors' responses when facing a suicide crisis, how they utilized aid networks to deal with their psychological issues, and the decision-making to look for mental health professional help.

\section{Method}

The study was a descriptive phenomenology study and aimed to uncover the experience of seeking psychological help in a small number of participants. The present study also elaborated on the challenges, obstacles, and risks experienced by the participants when they are looking for psychological help, as well as where they could obtain the help they were looking for.

The participants' experience in seeking help was explored with a phenomenological approach. Seven suicide survivors ( $\bar{x} 26$ years old) were involved in this study, obtained by snowball technique that emphasizes participants' involvement with maximum variation sampling. All participants were suicide survivors from the younger population and had accessed mental health service such as: primary care (Puskesmas), mental health clinic at the hospital, and crisis center that provides psychological counseling service. The participants' characteristics are presented in Table 1.

\section{Table 1.}

Participants' Characteristics

\begin{tabular}{ccccc}
\hline Participant & Sex & $\begin{array}{c}\text { The age of the first } \\
\text { attempt }\end{array}$ & $\begin{array}{c}\text { Recurring } \\
\text { attempt }\end{array}$ & $\begin{array}{c}\text { Access to } \\
\text { professionals }\end{array}$ \\
\hline P1 & Male & 20 & Yes & PG, PR \\
P2 & Female & 19 & Yes & PG \\
P3 & Female & 20 & Yes & PG \\
P4 & Female & 21 & No & PG, PR \\
P5 & Female & 22 & No & PG \\
P6 & Female & 18 & No & GP, FC \\
P7 & Male & 20 & No & PG, PR \\
\hline
\end{tabular}

Notes:

PG: Psychologist; PR: Psychiatrist; GP: General Physician; FC: Family Counselor 
Data collection was done using semi-structured interviews, both in-person and via teleconference, from July 2020 to January 2021. The questions proposed centralized on the experience of a suicide crisis, the decision-making in help-seeking, and help evaluation. For example "Tell me about what happened at that time?", "How did you decide to seek help to deal with those problems?", "What did you expect from that help?", and "How is your assessment about the advice or help that was given?" The interviews were done in 3 to 4 meetings for 50 to 70 minutes in each meeting. Written informed consent was given to each participant along with a verbal explanation. All participants received information about the study's objective, what was expected from the participants, potential risks, and the possibility to withdraw from the study. All of the participants also provided consent for interview recording before data collection was done. This study was reviewed and granted ethical clearance from the Ethics Committee of the Faculty of Psychology at Universitas Gadjah Mada.

The data analysis was done using phenomenological descriptive analysis (Giorgi et al., 2017) with the objective to identify the meaning according to the essence of participants' experiences in looking for psychological help. The analysis was done in a collaborativeindependent manner by involving trained assistants. The first step was reading the transcripts and interview notes several times to build familiarity and grasp the dynamics of the data. Then, the units of meaning were developed by employing psychological reduction in the transcript. After that, those meaning units were transformed into a psychological description. My team and I did intensive discussions to synthesize the themes and descriptive meaning of all of the participants. To guard the data rigor, the study conducted: participants' recruitment based on the study's objective, independent data analysis with colleagues, and participant involvement in confirming the themes and findings. Notes and the transcripts of participants' stories were input into the spreadsheet for further analysis by changing the participants' names and identities beforehand.

\section{Results}

Four themes are identified as domains that are related to the dynamic of help-seeking in facing suicide crisis and reconstructing resilience. The sources of help identified by the participants are meaningful in help-seeking: independent help, closest people, sociocultural resources, and institutional. Themes that are the essential meaning of experience will be explained further.

The sources of psychological help in the present study referred to the initial source of a person to obtain support or psychological help needed related to the mental health crisis that they experienced. It is necessary to note that although all participants were from the young group who was connected to virtual reality, but during the crisis, they did not utilize various online psychological services available in numerous platforms. Dysfunctional interpersonal skills did not affect the dismissive attitude towards suicide crisis, but it depends on the individual characters, whether the person is more closed off to 
others regarding the situation he is in. All names presented in this research report are in pseudonyms.

\section{Table 2.}

Sources of Psychological Help in Suicide Survivor

\begin{tabular}{|c|c|c|c|}
\hline Self-help & Close relationships & Socio-cultural & Institutional \\
\hline $\begin{array}{l}\text { relaxation, praying, } \\
\text { exercising, } \\
\text { meditation, yoga, } \\
\text { raising pet, } \\
\text { gardening, doing } \\
\text { hobby }\end{array}$ & $\begin{array}{l}\text { close friends, } \\
\text { partner, relatives, } \\
\text { parents, sibling }\end{array}$ & $\begin{array}{l}\text { teacher, preacher, } \\
\text { yogi, public figure, } \\
\text { clairvoyant }\end{array}$ & $\begin{array}{l}\text { hospital, crisis } \\
\text { center, public health } \\
\text { centers, clinic, } \\
\text { doctor, psychiatrist, } \\
\text { psychologist, } \\
\text { counsellor }\end{array}$ \\
\hline
\end{tabular}

\section{Self-help}

This theme emphasizes the participants' efforts to handle a crisis on their own. The efforts done include relaxation, praying, increasing activities, or doing hobbies (e.g.: watching movies, sports, and arts and crafts). Self-help activities are done according to the common information or knowledge obtained from websites, podcasts, character development books, or suggestions from their close people. In addition to doing the activities to avoid stressful situations, they also direct the individuals to practice seeing problems in a broader perspective, accepting and loving themselves, and achieving self-recovery. An example was given by $\mathrm{P} 4$ who had been experiencing depression for a year. She joined meditation and yoga groups that made her have more activities.

"Those activities help me not to focus too much on (my) problems. So, I have more opportunities to do other things and rehabilitate myself."

Self-help is done by combining common pieces of advice, character development, or hobbies with an objective to gain psychological compensation by reducing tensions as well as finding a sense of safety in personal space. Self-help is done without the need for professional assistance and done as a part of self-management strategies. Self-help also aims for achieving emotional and cognitive tranquility, therefore the person is not drifting in the problems and the sources of distress. The theme "self-help" actually explains the participants' attitude to solve problems independently before involving others. P1 revealed that "As long as I'm still able to solve it on my own, I do it myself." Although self-help does not resolve the issues, all participants considered the effort as helpful in managing unpleasant emotions (e.g.: feeling down, blue, worried, and confused). As an example, P6 said: 
"...how I can control emotion so I'm not feeling sadness all the time. Now I have Brownie (her cat's name) who can cheer me up too. If I'm not feeling down, at least I can still enjoy life at that time."

All participants experienced obstacles to telling or sharing their turmoil and bitterness with other people. They considered the problems that they faced were not worth acknowledgment by others or that those problems were not complicated enough to involve other people. This assumption was a form of shame that often inhibited participants to search for help. They were agitated by the general perception that expects someone to have the tenacity in facing burdens, instead of telling other people which may reflect the personality of a meek and pathetic.

\section{Close relationships}

Interpersonal relation encompasses factors that are paradoxical in the contribution to the suicide act. Participants perceived that their suicide crisis arose due to social stressors (e.g., family, parents, or partners). Nonetheless, the study found that participants with suicide crises also shared the burdens with their closest people. This closeness is not merely familial or blood relation and is instead marked by emotional relations, attachment, and trust. P1, for example, all this while only shared his crises to a close friend whom he knew since high school and he felt safe about it.

"If I feel like I need help, somehow either Nana or Sasa would come across my mind. Even in each time, the urge to kill myself comes up, I feel that they are very reliable in making me feel safe."

The openness and involvement of closest people are likelier to happen when the person has psychological closeness to certain people. This study found that help source from close relationships was obtained from substitute relations because primary relations within the family were considered damaged. The new relationships are represented in friendships, community, kinship, and romantic relationships. This closeness is also marked by a sense of security from judgment and rejection of the situations being experienced. The motive of involving close relationships was admitted by the participants to serve faster emotional support and the lower risk of loss. P5 explained that,

"I only think about one person, Intan, whom to me, all this time, only her who can understand. I feel heard by her, and not judged by the smears happening with my family."

So was P7 who found a sharing partner in a meditation community. 


\section{NURDIYANTO \& SUBANDI II PSYCHOLOGICAL HELP IN SUICIDE CRISIS}

"It turns out that he also had a suicide experience, but he recovered from his condition faster. We met and talked about our depression experience. He listens to me and even asks about my strange thoughts... he helps me to be open about my condition.

Despite promising benefits, the involvement of other parties within a crisis does not always yield sweet results, as it had been expected by P2 who had experienced an unpleasant disclosure event. The information, which was supposed to be a secret, was spread to her schoolmates and it caused her to develop trust issues with other people.

"I thought that my friend could be trusted to keep a secret, it turned out that she's a blabbermouth (telling the secret to others) who embarrassed me and made me feel easily suspicious with people."

\section{Socio-cultural}

Most participants decided to seek help from people or institutions that were considered to have legitimatization, role and influence, or charisma accepted by the community and culture. This theme is a synthesis of help resources given, such as teacher or lecturer, religious figures (kyai, priest, nun), or people who are considered to be crucial figures within the community where the participants resided. P6 intensively contacted her Islamic teacher (kyai) in an Islamic boarding school, related to the psychological crisis that she experienced due to her parents' conflict.

"The kyai definitely knows better solution for me. He can be said, old, from his life experience he has encountered problems like what I experience. From a knowledge perspective, it is unquestionable. I went there because I wanted to know how religion can provide a suitable solution for me."

Or P4's experience in meeting several different religious scholars.

"At that time, I went to religious experts first, to Quran teachers, and also to a priest. Because of them, all this time I can see my own blind spot, what if it is a God's test that I haven't realized? Only after that, after awhile consulting with them, I consulted to a psychologist."

An interesting finding related to the involvement of this health resource is that the participants' motivation was not only to resolve or reduce the crisis tension but also to receive structural support and practical solutions for the problems being faced. Participants asked their lecturers' aid for solutions to the academic problems (P1, P3, P4). P3, P4, and P7 
also routinely visited spiritual teachers to receive spiritual support and enhancement through consultation, prayers, and recommended religious rituals.

\title{
Institutional
}

The last theme was revealed by all of the participants, namely their experience in accessing formal health facilities and psychological services. Institutional psychological help is given by centers or mental health personnel; such as doctors, psychiatrists, counsellors, primary care centers, or crisis centers. Access to institutional help is given so that individuals in need can receive psychological counselling, medication, or various therapies that they believe can resolve or reduce crisis. P1, for example, preferred to receive help from a psychiatrist practicing at a hospital when he could not manage his condition,

\begin{abstract}
"I will go to a psychiatrist if I feel that I'm having a "mental breakdown", that (I am) really sad and crying hard. Also sometimes when (I'm) manic and cannot sleep at all, walking, or running without feeling tired at all. Or when it is already an emergency condition, such as bleeding because I cut (myself) too deep."
\end{abstract}

The study also noted that public health center is popular health institution that is used by most participants in finding professional help. Except for P6, all participants had accessed psychological help integrated into the local public health center's system. Most participants could receive professional mental health aid with this scheme and easily access it, from location and financial perspectives.

Institutional help-seeking proposes several obstacles; including barriers in information, accessibility, and financial. P6 was a psychology student at a university in Semarang. However, when she was struggling with her crisis, she never accessed the formal service. She herself realized that mental health personnel can offer help in the crisis that she experienced. However, P6 felt that she did not have enough money to access the help.

"I never went there because I don't have enough money. My problem will not be resolved in two or three meetings. It takes a lot of money."

\section{Discussion}

The study was done to explore the meaning and experience of suicide survivors when seeking psychological help. Through the descriptive phenomenology approach, the study synthesized four sources of psychological help: self-help, close relationships, socio-cultural, and institutional. Inductive analysis revealed that the sources of psychological help for suicide ideation and crisis are the combination and compromise of individual beliefs, social influences, and professional competence. 
Previous studies have mapped internal and structural factors as the source of mental health aid (Barker et al., 2005). This internal factor encompasses perception and belief related to mental health issues, personal coping skills, and mental health knowledge (Altweck et al., 2015; Kutcher et al., 2016), as well as attitude and openness on mental health issues (Cheng et al., 2015). On the other hand, structural factors such as perspective on cultural and communal norms towards help-seeking behavior, family and close people's facilitation, healthcare system within the community (school, workplace), to reference mechanism, insurance, and funding in the healthcare service (Barker et al., 2005; Call et al., 2010). Despite that, both individual and structural factors play a crucial role in determining when and how an individual with a suicide crisis decides to access psychological help and support resources.

Psychological help-seeking is every action done to obtain the help that is not only limited to formal health aid, but also affective, psychosocial, problem-solving, and social service supports that can improve one's welfare (Barker, 2007). The present study affirms previous findings that explained how psychological help-seeking contains potential plural and reflective help sources based on evaluation and the impact of help being received (Good et al., 2019; Subandi et al., 2020). Although Rickwood et al. (2007) had established that psychological help source is a combination of formal and informal help sources, but the argument over-simplified and overlooked the dynamics of psychological help-seeking. As the study showed, help-seeking has actually been kick-started when the tension resolution is done independently.

This study showed that psychological help-seeking in suicide crisis issues cannot be separated from the variety of help sources, complexity in the mental health service, and the increased stigmatization. This paper aims to establish that the source of psychological help for a person with a suicide crisis has started when the self-help is done with the involvement of close people, socio-cultural figures, and professionals. All of these efforts are done to receive support (affective, evaluative, and instrumental), based on the survivor's expectation.

Studies done in the Javanese context had explained that psychosocial stressors become the main source of mental health crisis and suicide ideation (Nurdiyanto, 2021; Nurtanti et al., 2020). Despite that, relationship intimacy and connection with close people can be a protective factor that develops self-resilience (Nurdiyanto, 2020). Relational closeness is a source of support as well as a social network that can build emotional ties, trust, and attachment. This finding also stresses that the openness of survivor towards their closest people contribute to preventing risky and more fatal behaviors

The suicide crisis is also not only considered as a medical-physical problem but a comprehensive issue that involves spiritual and social aspects. Attributive knowledge and evaluation contribute to crisis resolution, treatment efforts, and mental health help-seeking (Good et al., 2019). The evaluation of the cause determines how a suicide crisis is managed by emphasizing social integration and a spiritual approach. We can understand that people 
who experience mental health crises often involve religious figures and key people in the community rather than resolving the mental health problems than professionals (Cakar \& Savi, 2015; Widayanti et al., 2020).

Early assessment is a crucial phase at the beginning of help-seeking action to recover the patient's condition. Subandi et al. (2020) found that the analysis of the cause of the disorder becomes the starting point for the decision making in help-seeking, whether using professional (doctor, psychiatrist) or non-professional help. An analysis by Widayanti et al. (2020) also elaborated that help-seeking health behavior in Indonesian society is more fluid; medical treatment is considered complementary to the broader recovery effort. The selection of help source is also inconsistent; family or patient can switch from one source to another based on the evaluation towards the help or the help received from the source. Professional help would be utilized when the family realizes that non-professional treatment does not result in improvement, so is otherwise. The selection of help sources does not only aim to alleviate the crisis, but also restore biological, mental, social, and spiritual harmony (Subandi et al., 2020).

Other than using professional sources of help, the study found that help-seeking in non-professionals and self-help are more common to be done. Although participants revealed dissatisfaction with the results and evaluations towards the non-institutional source of help, they still made them their primary options. Some of the reasons include: having personal closeness, considering the source of help (close relationships and sociocultural) as an integral part of the community, and the presence of trust towards figures that can reduce psychosocial stressors. Nurhayati and Widowati (2017) had estimated that around $30.4 \%$ of the respondents preferred traditional health services. So are Balinese (Kurihara et al., 2006); when it comes to treating a psychotic disorder, they choose to go to a traditional healer (balian) first before going to psychiatry service. Additionally, professional help is believed to incite negative views from the community which leads to labeling the person as "insane" or "troubled" (Rasyida, 2019). This study showed that mental health professionals are yet to be considered as the primary resource to solve psychological problems and suicide crises. Psychological help by mental health institutions still presents cultural discrepancies with the people and health system.

The researcher admits several limitations in the study. Data collection was done during the Covid-19 pandemic, therefore the interview could not be done face to face, which might lead to technical difficulties and issues in rapport building. Then, although a descriptive phenomenological study does not demand a certain number of participants and instead emphasizes the depth of its dynamic (Giorgi et al., 2017), the study suggests more experience elaborations of participants from different backgrounds (gender, setting). The present study also involved a small number of male participants which might imply the underrepresentation of suicide crisis in men. In addition, four of the participants had a background in psychology education that could be considered in influencing their conscience to seek psychological help. The study only captures the psychological help- 
seeking as an adaptive coping strategy and does not report on seeking professional help or contra-productive mechanism of crisis resolution. In the end, with the large variations of culture in Indonesia, studies about psychological help-seeking must be broadened by encompassing sectors that have yet to be studied.

\section{Conclusion}

The study found phenomenological themes that are identified as the sources of psychological help when a suicide survivor experiences suicide crisis: self-help, close relationships, sociocultural, and institutional. Before deciding on using the help provided by professional and formal personnel, they make an attempt to deal with crises independently or involving non-professionals. Despite that, the help-seeking process in suicide crisis is not linear. Instead, it happens spirally and reflectively, based on the perception of the cause of crisis and evaluation towards the help received. The inductive analysis also underscores that the four sources of psychological help are the combination and compromising mechanism of an individual's belief, social influences, and perception of professional competence.

\section{Suggestion}

The study proposes several practical recommendations. An individual with a suicide crisis is encouraged to utilize various help sources, instead of bottling up the problems and letting them pass. Then, the mental health campaign and literacy programs should encompass the development of adaptive coping skills, openness in help-seeking, and the anti-stigmatization of mental health. The study also provides crucial suggestions for cross-sector efforts; providing psychological service that can be accessed by many people.

\section{Acknowledgement}

This research is part of a project thesis at the Faculty of Psychology, UGM. Thank you for all participants who allowed me to hear about their experiences. For this kindness, I feel deeply indebted. Also, thanks to Arka Nareswari (Center for Indigenous \& Cultural Psychology, Universitas Gadjah Mada), who was also involved in the data analysis.

\section{Authors'contribution}

FAN contributed to the study's design, data collection, analysis, report of findings and wrote the manuscript. S, as supervisor, provided guidance and advice related to the research.

\section{Conflict of interest}

I also declare no conflict of interest that can influence this study.

\section{Funding}

The study did not receive or use funding from any party. 


\section{orCid ID}

F. A. Nurdiyanto 0000-0003-4353-2501

Subandi 0000-0001-6655-0038

\section{References}

Altweck, L., Marshall, T. C., Ferenczi, N., \& Lefringhausen, K. (2015). Mental health literacy: A cross-cultural approach to knowledge and beliefs about depression, schizophrenia and generalized anxiety disorder. Frontiers in Psychology, 6(1272), 117. https://doi.org/10.3389/fpsyg.2015.01272

Barker, G. (2007). Adolescents, social support and help-seeking behaviour: An international literature review and programme consultation with recommendations for action. In WHO Discussion Papers on Adolescence. https://apps.who.int/iris/handle/10665/43778

Barker, G., Olukoya, A., \& Aggleton, P. (2005). Young people, social support and helpseeking. International Journal of Adolescent Medicine and Health, 17(4), 315-335. https://doi.org/10.1515/IJAMH.2005.17.4.315

Cakar, F. S., \& Savi, S. (2015). An exploratory study of adolescent's help-seeking sources. Procedia - Social and Behavioral Sciences, 159, 610-614. https://doi.org/10.1016/j.sbspro.2014.12.434

Call, J. B., Shafer, K., Morgan, A. J., Jorm, A. F., Hanlon, C., Wondimagegn, D., Alem, A., Pagura, J., Fotti, S., Katz, L. Y., Sareen, J., Oh, E., Mathers, M., Hiscock, H., Wake, M., Bayer, J., Rickwood, D., Deane, F. P., Wilson, C. J., ... Conrad-Hiebner, A. (2010). Perceived barriers and facilitators to mental health help-seeking in young people: A systematic review. Australian and New Zealand Journal of Psychiatry, 10(1), 281-293. https://doi.org/10.1007/s10560-013-0321-5

Cheng, H. L., Mcdermott, R. C., \& Lopez, F. G. (2015). Mental health, self-stigma, and helpseeking intentions among emerging adults: An attachment perspective. The Counseling Psychologist, 43(3), 463-487. https://doi.org/10.1177/0011000014568203

Cornally, N., \& McCarthy, G. (2011). Help-seeking behaviour for the treatment of chronic pain. British Journal of Community Nursing, 16(2), 90-98. https://doi.org/10.12968/bjen.2011.16.2.90

Czyz, E. K., Horwitz, A. G., Eisenberg, D., Kramer, A., \& King, C. A. (2013). Self-reported barriers to professional help seeking among college students at elevated risk for suicide. Journal of American College Health, 61(7), 398-406. https://doi.org/10.1080/07448481.2013.820731

David, E. J. R. (2010). Cultural mistrust and mental health help-seeking attitudes among Filipino Americans. Asian American Journal of Psychology, 1(1), 57-66. https://doi.org/10.1037/a0018814

Freeman, A., Mergl, R., Kohls, E., Székely, A., Gusmao, R., Arensman, E., Koburger, N., 


\section{NURDIYANTO \& SUBANDI II PSYCHOLOGICAL HELP IN SUICIDE CRISIS}

Hegerl, U., \& Rummel-Kluge, C. (2017). A cross-national study on gender differences in suicide intent. BMC Psychiatry, 17(234), 1-11. https://doi.org/10.1186/s12888-017-1398-8

Gilchrist, H., \& Sullivan, G. (2006). Barriers to help-seeking in young people: Community beliefs about youth suicide. Australian Social Work, 59(1), 73-85. https://doi.org/10.1080/03124070500449796

Giner, L., Guija, J. A., Root, C. W., \& Baca-Garcia, E. (2016). Nomenclature and definition of suicidal Behavior. In P. Courtet (Ed.), Understanding suicide from diagnosis to personalized treatment (pp. 3-17). Springer International Publishing Switzerland. https://doi.org/10.1007/978-3-319-26282-6_1

Giorgi, A., Giorgi, B., \& Morley, J. (2017). The descriptive phenomenological psychological method. In C. Willig \& W. S. Rogers (Eds.), The SAGE handbook of qualitative research in psychology (2nd ed., pp. 176-192). SAGE Publications Ltd.

Good, B. J., Marchira, C. R., Subandi, M. A., Mediola, F., Tyas, T. H., \& Good, M.-J. D. (2019). Early psychosis in Indonesia: reflections on illness and treatment. International Review of Psychiatry, 31(5-6), 510-522. https://doi.org/10.1080/09540261.2019.1604495

Human Rights Watch. (2016). Living in hell: Abuses against people with psychosocial disabilities in Indonesia. https://www.hrw.org/id/report/2016/03/20/287718

Kementerian Kesehatan RI. (2016). Perilaku berisiko kesehatan pada pelajar SMP dan SMA di Indonesia. Badan Penelitian dan Pengembangan Kesehatan Kementerian Kesehatan RI.

http://www.who.int/ncds/surveillance/gshs/GSHS_2015_Indonesia_Report_Bahasa .pdf?ua $=1$

Kurihara, T., Kato, M., Reverger, R., \& Tirta, I. G. R. (2006). Pathway to psychiatric care in Bali. Psychiatry and Clinical Neurosciences, 60(2), 204-210. https://doi.org/10.1111/j.1440-1819.2006.01487.x

Kutcher, S., Wei, Y., \& Coniglio, C. (2016). Mental health literacy: Past, present, and future. The Canadian Journal of Psychiatry, 61(3), 154-158. https://doi.org/10.1177/0706743715616609

Luoma, J. B., Martin, C. E., \& Pearson, J. L. (2002). Contact with mental health and primary care providers before suicide: A review of the evidence. American Journal of Psychiatry, 159(6), 909-916. https://doi.org/10.1176/appi.ajp.159.6.909

Nurdiyanto, F. A. (2020). Masih ada harapan: Eksplorasi pengalaman pemuda yang menangguhkan bunuh diri. Persona: Jurnal Psikologi Indonesia, 9(2), 369-384. https://doi.org/10.30996/persona.v9i2.3995

Nurdiyanto, F. A. (2021). Explanatory model bunuh diri pada orang Jawa. (Master's thesis). Universitas Gadjah Mada, Yogyakarta.

Nurhayati, \& Widowati, L. (2017). The use of traditional health care among Indonesian family. Health Science Journal of Indonesia, 8(1), 30-35. https://doi.org/10.22435/hsji.v8i1.5600 
Nurtanti, S., Handayani, S., Ratnasari, N. Y., Husna, P. H., \& Susanto, T. (2020). Characteristics, causality, and suicidal behavior: A qualitative study of family members with suicide history in Wonogiri, Indonesia. Frontiers of Nursing, 7(2), 169178. https://doi.org/10.2478/fon-2020-0016

Owens, C., Lambert, H., Donovan, J., \& Lloyd, K. R. (2005). A qualitative study of help seeking and primary care consultation prior to suicide. British Journal of General Practice, 55(516), 503-509.

Pitman, A., \& Osborn, D. P. J. (2011). Cross-cultural attitudes to help-seeking among individuals who are suicidal: New perspective for policy-makers. British Journal of Psychiatry, 199(1), 8-10. https://doi.org/10.1192/bjp.bp.110.087817

Rasyida, A. (2019). Faktor yang menjadi hambatan untuk mencari bantuan psikologis formal di kalangan mahasiswa. Persona: Jurnal Psikologi Indonesia, 8(2), 193-207. https://doi.org/10.30996/persona.v8i2.2586

Rickwood, D. J., Deane, F. P., \& Wilson, C. J. (2007). When and how do young people seek professional help for mental health problems? The Medical Journal of Australia, 187(7), S35-S39. https://doi.org/10.5694/j.1326-5377.2007.tb01334.x

Rickwood, D., \& Thomas, K. (2012). Conceptual measurement framework for help-seeking for mental health problems. Psychology Research and Behavior Management, 5, 173-183. https://doi.org/10.2147/PRBM.S38707

Seamark, D., \& Gabriel, L. (2018). Barriers to support: A qualitative exploration into the help-seeking and avoidance factors of young adults. British Journal of Guidance and Counselling, 46(1), 120-131. https://doi.org/10.1080/03069885.2016.1213372

Subandi, M. A., Praptomojati, A., Marchira, C. R., Good, M.-J. D., \& Good, B. J. (2020). Cultural explanations of psychotic illness and care-seeking of family caregivers in Java, Indonesia. Transcultural Psychiatry, 1-11. https://doi.org/10.1177/1363461520916290

Widayanti, A. W., Green, J. A., Heydon, S., \& Norris, P. (2020). Health-seeking behavior of people in Indonesia: A narrative review. Journal of Epidemiology and Global Health, 10(1), 6-15. https://doi.org/10.2991/jegh.k.200102.001

World Health Organization [WHO]. (2021). Suicide worldwide in 2019: Global health estimates. https://www.who.int/publications/i/item/9789240026643 